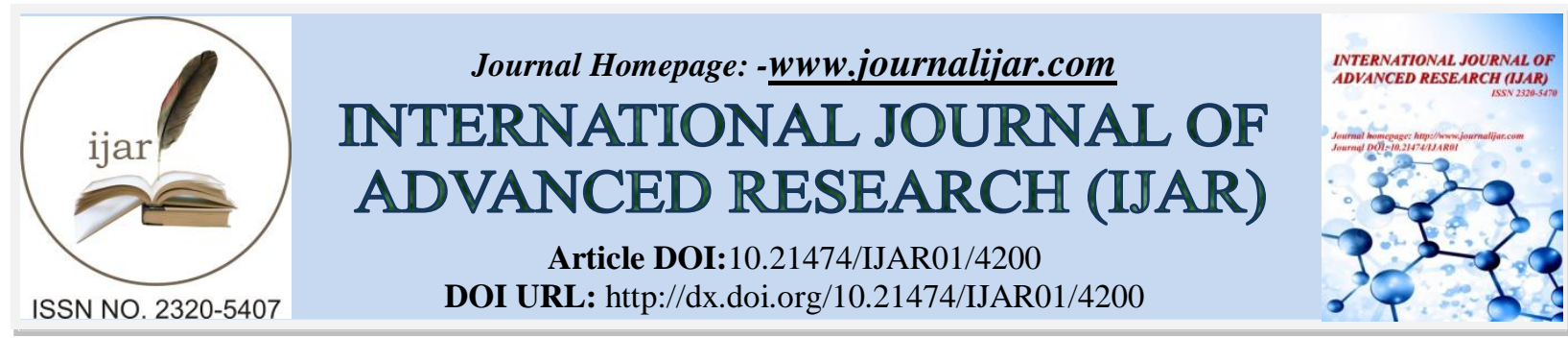

RESEARCH ARTICLE

\title{
TOXICITY OF ACACIA NILOTICA FRIUTS WATER EXTRACT AGANIST BIOMOPHLARIA SNAILS
}

1. Military hospital central lab.

2. Department of Parasitology, Faculty of Medical Laboratory Sciences, Alneelain University, Khartoum, Sudan.

3. Medicinal and Aromatic plants Research institute, National Center for Research,

4. University of Khartoum, faculty of sciences, Department of zoology.

\section{Manuscript Info}

(..........................

Manuscript History

Received: 13 March 2017

Final Accepted: 11 April 2017

Published: May 2017

\section{Abstract}

Background: In the Sudan, many local plants are screened and tested in the laboratory and proved to have molluscicidal activity. Molluscicides are crucial for the control of schistosomiasis and other snail-borne infections. The need to use plants has received increased interest as an inexpensive technology because of the high cost of synthetic compounds for snail control in the endemic areas of poor nations of the world.

The aim of this study was to investigate the toxic effect of the aqueous extract of Acacia nolitica against Biomphalaria snails under laboratory conditions.

Methods: A true experimental study was done to find out the toxic effect of the aqueous extract of Acacia noliticaon Biomphalaria snails. An aqueous extract from fruit was powdered and strained and was used as stock solution. Serial concentrations 10,000, 5,000, 1,000, 500, 250 and 125ppm were tested on Biomphalaria snails. The snails were subjected to the extract for $24 \mathrm{hrs}$. After that the Lc50 were obtained.

Results: The mortality rate was found to be ranging between $40 \%$ and $100 \%$. Three trials were made and the average was taken. The LC50 is 83.39

Discussion: This result proves the say; In Sudan Acacia nolitica fruit had been used as anti-parasitic agent. The plant extracts were found to exhibit antidiarrhoeal, antibacterial, antimalarial and inhibition of lipid peroxidation,Acacianilotica is known for high amounts of tannins, falvonoides, polysaccharides, and organic acids ${ }^{(1),(2)}$. Because of its impacts on other aquatic fauna and the environment, quest for safer pesticides has attracted researchers to look into plants with pesticides properties.

The aqueous extract of this tree has been found to be potent in controlling Biomphalaria snails. It is recommended to do more research on the plant extracts in water and other solvents. Yet, since the chemical contents of plants depend mainly on soil composition, it is of paramount importance to test extracts of Acacia nilotica from different geographical areas. 


\section{Introduction:-}

Schistosomiasis is one of the most widely spread parasitic infections transmitted by snails. It occurs in most countries of tropical Africa, Middle East, Central and South America, the Caribbean and the Far East.

The disease increases with the introduction of large scale irrigation schemes, whenever water-filled canals become the breeding sites of snails of which various act as the intermediate host of the parasite ${ }^{(3)}$, an estimated 200 million people in the world are infected from a total of 600 million at risk. Ten percent of the infected people develop severe clinical diseases (20 million). Of the remaining 180 million people, an estimated 50-60\% also has symptoms -a public health problem of enormous proportions ${ }^{(4)}$. Other flukes of public and veterinary importance are also transmitted by snails. Chemical, environmental and biological methods were used in snail control for decades.

The use of aqueous plant extracts with pesticides properties for insect pest control in crops has been well documented $^{(5)}$.

Acacia niloticaFamilyMimosaceae,English name (Egyptian thorn, Prickly acacia) Arabic name (Sunut tree, Garad fruit ${ }^{(6)}$. Acacia nilotica is widely distributed in sub tropical and tropical Africa. Various flavonoids and phenolic compounds have been isolated from the flowers, In Sudan the leaves and fruits are used against cough, Colds, diarrhea, scurvy, and toothache ${ }^{(7),(8)}$.The botanical molluscicides are of economic importance, especially in developing countries .Also, there is a continuous need to search for new plant species with ideal molluscicidal proprieties ${ }^{(9),(10)}$.

The number and types of the specific molluscicides used for controlling the snails are limited; they caused different environmental problems in addition to the toxic effects to non-target organisms ${ }^{(11)}$.

In this study, it was intended to find out the toxicity of the AcaciaNiloticaaqueous extract against Biomphalaria snails.

\section{Materials and Methods:-}

Materials:-

Plastic dishes 1000ML, strainers, beakers, Flasks, Measuring cylinders, wooden sticks.

\section{Methodology:-}

\section{Snail Collection:-}

Snails were collected from different sites in Khartoum State (Selate Northern Canal 18\&7, Selate Southern canal B, Aldoma area, Alshagara, Alkalakla Albaiara \& Jabil Awleia)

Acacia Nilotica fruits preparation:-

Acacia Nilotica was collected, dried in shaded place and was powdered using a clean electric blender .

\section{Preparation of aqueous extract:-}

Ten grams of each coarsely powdered plant is macerated in $800 \mathrm{ml}$ of distilled water for 24hours at room temperature $\left(25^{\circ} \mathrm{C}\right)$. The extract is filtered and the volume is adjusted to $1000 \mathrm{ml}$ with distilled water to give stock solution extract of $10 \mathrm{grams} / \mathrm{litre}$ i.e. $10,000 \mathrm{ppm}$ of the powdered plant material. Further serial dilutions were done from the above stock solution to which snails are exposed i.e. 10,000, 5,000, 1,000, 500, 250 and 125ppm.

\section{Experimental Methods:-}

Ten snails were placed in alcohol $50 \mathrm{ml}$ volume beaker containing $50 \mathrm{ml}$ of each concentration. Ten snails are then added to each beaker. Ten snails are put in a separate beaker containing $50 \mathrm{ml}$ of distilled water as a control. The beakers are left in the laboratory for 24 hours and then snails were transferred into beakers containing $50 \mathrm{ml}$ of distilled water for recovery. They are examined after 24 hours noting the dead as well as live ones. A snail is confirmed dead if it was remained immobile after having been observed for five minutes with the aid of 10 magnification hand lens and either retracted well into or hanged out of the shell, with the body and shell discoloured.

The experiments were conducted at room temperature $\left(28-30^{\circ} \mathrm{C}\right)$, using a mercuric thermometer. Each experiment was repeated three times. 


\section{Statistical Analysis:-}

Probit regression analysis (SPSS/inc) was carried out for the plant tested to determine the $\mathrm{Lc}_{50}$ values. The slope of the regression line was used to assess the effect of the extract; the steeper the slope, the more lethal the plant molluscicide effect.

\section{Results:-}

The results of the experiments were analyzed using the analysis of variance and log probit analysis.

Normal graph was used instead of the logarithmic graph because of unavailability of the logarithmic scale graph papers. Table 1-3 shows the data which demonstrate mortality rates among snails exposed to different concentrations of the aqueous extract of each plant i.e. 10000, 5000, 1000, 500, 250 and 125ppm. Table 4 shows that the average mortality of Biomphalaria snails subjected to aqueous extract of acacia niloticafor the three trials ranged between 40\%-97\% (probit units 4.75-6.83). It has also been shown that there was no mortality in the control of each trial; hence no correction for mortality was needed. The molluscicidal activity is decreased with the decrease in concentration.

Table 1:- Mortality of biomphalaria snail subjected with water extract of acacia nilotica fruits(trail 1), Khartoum, 2017

\begin{tabular}{|l|l|l|l|l|l|l|l|}
\hline $\begin{array}{l}\text { Conc. } \\
\text { PPM }\end{array}$ & Log(C\%) & Live & Dead & prop & Correct prop & Logit & Probit unit \\
\hline 10000 & 4 & 0 & 10 & 1 & 1.00 & & \\
\hline 5000 & 3.7 & 0 & 10 & 1 & 1.00 & & \\
\hline 1000 & 3 & 0 & 10 & 1 & 1.00 & & \\
\hline 500 & 3.7 & 2 & 8 & 0.8 & 0.80 & 1.39 & 5.84 \\
\hline 250 & 2.4 & 3 & 7 & 0.7 & 0.70 & 0.85 & 5.52 \\
\hline 125 & 2.1 & 5 & 5 & 0.5 & 0.50 & 0.00 & 5.00 \\
\hline 0 & & 10 & 0 & 0 & & & \\
\hline & & & & & Slope: & 0.73 & \\
\hline & & & & Intercept: & -1.25 & \\
\hline & & & & Test value & 0.00 & \\
\hline & & & & & Logit (C\%) & 1.71 & \\
\hline & & & & & LC50 & 51.52 & \\
\hline
\end{tabular}

Table 2:- Mortality of biomphalaria snail subjected with water extract of acacia nilotica fruits(trail 2), Khartoum, 2017

\begin{tabular}{|l|l|l|l|l|l|l|l|}
\hline $\begin{array}{l}\text { Conc. } \\
\text { PPM }\end{array}$ & Log(C\%) & Live & dead & Prop & Correct Prop & Logit & Probit \\
\hline 10000 & 4 & 0 & 10 & 1 & 1.00 & & \\
\hline 5000 & 3.7 & 0 & 10 & 1 & 1.00 & & \\
\hline 1000 & 3 & 0 & 9 & 0.9 & 0.90 & & \\
\hline 500 & 3.7 & 2 & 9 & 0.9 & 0.90 & 2.20 & 6.28 \\
\hline 250 & 2.4 & 3 & 6 & 0.6 & 0.60 & 0.41 & 5.25 \\
\hline 125 & 2.1 & 5 & 4 & 0.4 & 0.40 & -0.41 & 4.75 \\
\hline 0 & & 10 & 0 & 0 & & & \\
\hline & & & & & Slope: & 1.55 & \\
\hline & & & & & Intercept: & -3.50 & \\
\hline & & & & Test value & 0.00 & \\
\hline & & & & & logit(C\%) & 2.26 & \\
\hline & & & & & LC50 & 181.52 & \\
\hline
\end{tabular}


Table 3:- Mortality of biomphalaria snail subjected with water extract of acacia nilotica fruits(trail 3), Khartoum, 2017

\begin{tabular}{|l|l|l|l|l|l|l|l|}
\hline $\begin{array}{l}\text { Conc. } \\
\text { PPM }\end{array}$ & $\log (\mathbf{C \%})$ & Live & dead & Prop & Correct Prop & Logit & Probit \\
\hline 10000 & 4 & 0 & 10 & 1 & 1.00 & & \\
\hline 5000 & 3.7 & 0 & 10 & 1 & 1.00 & & \\
\hline 1000 & 3 & 0 & 10 & 1 & 1.00 & & \\
\hline 500 & 3.7 & 2 & 8 & 0.8 & 0.80 & 1.39 & 5.84 \\
\hline 250 & 2.4 & 3 & 6 & 0.6 & 0.60 & 0.41 & 5.25 \\
\hline 125 & 2.1 & 5 & 3 & 0.3 & 0.30 & -0.85 & 4.48 \\
\hline 0 & & 10 & 0 & 0 & & & \\
\hline & & & & & Slope: & 1.20 & \\
\hline & & & & & Intercept: & -2.97 & \\
\hline & & & & & Test value & 0.00 & \\
\hline & & & & & logit(C\%) & 2.47 & \\
\hline & & & & & LC50 & 294.79 & \\
\hline
\end{tabular}

Table 4:- Mortality of biomphalaria snail subjected with water extract of acacia nilotica fruits (Average of the three trails), Khartoum, 2017

\begin{tabular}{|l|l|l|l|l|l|l|l|l|}
\hline $\begin{array}{l}\text { Conc. } \\
\text { PPM }\end{array}$ & $\begin{array}{l}\text { Log } \\
(\mathbf{C})\end{array}$ & live & dead & Mortality\% & prop & $\begin{array}{l}\text { Correct } \\
\text { Prop }\end{array}$ & Logit & Probit \\
\hline 10000 & 4.0 & 0 & 30 & 100 & 1.00 & 1.00 & & \\
\hline 5000 & 3.7 & 0 & 30 & 100 & 1.00 & 1.00 & & \\
\hline 1000 & 3.0 & 0 & 29 & 97 & 0.97 & 0.97 & 3.37 & 6.83 \\
\hline 500 & 3.7 & 2 & 25 & 83 & 0.83 & 0.83 & 1.61 & 5.97 \\
\hline 250 & 2.4 & 3 & 19 & 63 & 0.63 & 0.63 & 0.55 & 5.34 \\
\hline 125 & 2.1 & 5 & 12 & 40 & 0.40 & 0.40 & -0.41 & 4.75 \\
\hline 0 & & 10 & 0 & 0 & 0.00 & & & \\
\hline & & & & & & Slope & 1.46 & \\
\hline & & & & & & Intercept & -2.80 & \\
\hline & & & & & & Test value & 0.00 & \\
\hline & & & & & & logit(C\%) & 1.92 & \\
\hline & & & & & & LC50 & 83.39 & \\
\hline
\end{tabular}

\section{Discussion:-}

The need for using natural products in the control of schistosoma snails necessitated continuous research in this field especially products of plant origin. This effort aimed at finding the effect of the aqueous extract of Acacia nilotica on Biomphalaria snails.

Mortality rate of Biomphalaria snails was recorded after every 24-48 hrs.

Lethal concentration was observed between exposure time and different concentration of extracted fruit material of plants. The LC 50 values are tabulated in the tables.

\section{Recommendation:-}

1. Aqueous extract of Acacia niloticaisrecommended in the control of Biomphalaria snails.

2. Extraction and standardization of the active ingredient are important.

3. Studies on the toxic effect of extracts soluble in solvents other than water are also recommended.

\section{References:-}

1. El Tahir, A., Satti, G., Khalid, S. (1999) Antiplasmodial activity of selected Sudanese medicinal plants with emphasis on Acacia nilotica. Phytotherapy Research. 13, 474-478vitro immunomodulating properties of selected Sudanese medicinal plants. Journal of Ethnopharmacology $118: 26-34$

2. Saleem, A., Ahotupa, M., Pihlaja, K. (2001) Total phenolics concentration and antioxidant potential of extracts of medicinal plants of Pakistan. Zeitschrift fur Naturforschung (C) 56, 973-978. 
3. Kalhoro, I.B.2005.Developmental biology of the shistosoma haematobium in the intermediate host snail. A thesis submitted in partial fulfillment of the requirement for the degree of doctor of philosophy .

4. Ajaavi O, Orokoyo JT, Nezan JT, Ndirmbula BM, Kannike OA.

5. Laboratory assessment of the efficacy of some plant materials for the control of storage insect pests of cowpea. German J Agric Res. 1987;5(2):81-86.

6. oratory assessment of the efficacy of some plant materials for the control of storage insect pests of cowpea. German J Agric Res. 1987; 5(2):81-86.

7. Koko. S.W., M. Ahmed Mesaik., S. Yousaf, M. Galala., M. Iqbal Choudhary. (2008) In vitro immunomodulating properties of selected Sudanese medicinal plants. Journal of Ethnopharmacology $118: 26-$ 34

8. Agunu, A., Yusuf, S., Andrew, G., Umar Zezi, A., Aburahman, E. (2005) Evalutation of five medicinal plants used in diarrhoea treatment in Nigeria. Journal of Ethnopharmacology 101, 27-30.

9. Rani, P., Khullar, N. (2004) Antimicrobial evaluation of some medicinal plants for their anti-enteric potential against multi-drug resistant Salmonella typhi. Phytotherapy Research 18, 670-673.

10. McCullough FS, Gayral P, Duncan J, Christie J. Molluscicides in schistosomiasis control. Bulletin of the World Health Organization. 1980; 58:681-689.

11. Marston A, Hostettmann K. Review article No 6: Plant Mulloscicides. Phytochem. 1986; 24:639-652.

12. Buchs, W. V. Heimbach and E. Czanechi(1989). Effects of snail baits on non-target carabid beetles, in slugs and snails in world agriculture, BcBc monograph no 41, ed by Henderson, IF, British crop Protection Council, Farnham, Surrey UK, pp. 245-252. 